\title{
Anesthesia for outpatient spine surgery: a commentary
}

\author{
Dustin H. Massel, Krishna D. Modi, William W. Long and Kern Singh* \\ Department of Orthopaedic Surgery, Rush University Medical Center, Chicago, USA
}

\section{Commentary}

In the current medical climate aimed at reducing unnecessary hospitalization, hospital costs, and resource utilization, ambulatory care centers and outpatient surgical popularity are on the rise [1]. Technological advancements have allowed a shift in the surgical paradigm towards minimally invasive surgery with evidence demonstrating smaller incisions, reduced soft tissue injury, operative time, estimated blood loss, and postoperative pain, lower rates of complications, and improved postoperative patient function compared to their open counterparts [2-4]. Successful efforts to minimize soft tissue injury have resulted in faster recovery times, time to rehabilitation, and shorter length of hospital stay [5]. In effort to meet the growing demand of ambulatory surgery, anesthetic techniques have evolved to reduce perioperative morbidity and adverse medication side effects associated with general anesthesia as well as reduce postoperative pain in order to prevent overconsumption of narcotic medications.

Postoperative nausea and vomiting (PONV) is a major concern associated with general anesthesia affecting $20-35 \%$ of general surgery, and up to $80 \%$ of high-risk patients and may result in hospital admission following outpatient surgery $[1,6,7]$. Risk factors associated with PONV include female gender, age greater than 50-years-old, nonsmoking status, and a history of PONV or motion sickness $[1,6]$. In regards to anesthesia, an increased risk of PONV has been reported with use of volatile anesthetics, nitric oxide, and intra- or postoperative opioid medications. Similarly, it has been demonstrated that an increase in 30 minutes of operative time was associated with a $60 \%$ increase in PONV risk. In order to minimize risk, studies have demonstrated using regional anesthesia rather than general anesthesia and propofol for anesthesia induction are associated with a reduced baseline risk of PONV [6]. Similarly, avoiding volatile anesthetics or nitric oxide, and minimizing intra- and postoperative opiates are also associated with a reduced baseline risk. Postoperatively, administration of firstline antiemetics such as 5-hydroxytryptamine receptor antagonists (i.e. ondansetron) and steroid medications (i.e. dexamethasone) are commonly used in the prophylaxis and treatment of PONV. Additional concerns for outpatient surgical procedures result from postoperative pain control and the use of opiod medications. Common adverse effects associated with opiate use include nausea and vomiting, constipation, drowsiness, dizziness, and dry mouth. Reduction in postoperative morbidity associated with opiate consumption is largely the result of cyclooxygenase inhibitor and non-steroidal anti-inflammatory (NSAIDs) use [1].

In addition to decompression procedures such as laminectomy, facetectomy, foraminotomy, and discectomy, the senior surgeon commonly performs anterior cervical discectomy and fusion $(\mathrm{ACDF})$ in an ambulatory Surgicenter setting. In order to minimize complications and efficiently perform these procedures, the senior surgeon has employed a multidimensional approach to patient care, assembling a multidisciplinary team to adequately meet patient's needs. Based on experience and careful observation of outcomes, the senior surgeon and his team of anesthesiologists commonly use the following medications for his outpatient procedures: initially, midazolam and fentanyl are administered in the preoperative holding area for sedation and analgesia, respectively. Once the patient is brought to the operating room and situated on the operating table, a mixture of lidocaine and propofol are administered. Lidocaine is givento reduce the pain associated with a propofol injection, while propofol is given for sedation. Once the patient is asleep, a non-depolarizing neuromuscular blocker, such as vecuronium or rocuronium, is administered to paralyze the patient in order to perform endotracheal intubation. Maintenance anesthesia is accomplished with sevoflurane. A mixture of neostigmine and glycopyrrolate is administered postoperatively. Neostigmine is an acetylcholinesterase inhibitor working as the neuromuscular blocking reversal agent while glycopyrrolate is utilized to prevent the muscarinic side effects, such as bradycardia, associated with neostigmine use. Depending on patient comorbidities and history with anesthesia, the senior surgeon has also utilized succinylcholine for neuromuscular blockade and ketamine for maintenance.

Despite the popularity and effectiveness of outpatient and ambulatory spine surgery, it is important to recognize potential adverse effects associated with all aspects of the surgical experience. Proper patient selection and preparation for common surgical and anesthetic complications will result in reduced hospital admissions and postoperative patient morbidity. Through repetition and careful planning, the surgical team providing care in the outpatient setting has adjusted protocols and procedural timing to safely and efficiently meet their patient population's needs. While the combination of medications listed above and the senior surgeon's procedural experience has functioned for his patient population, an individualized treatment plan incorporating patient comorbidities, medical, surgical, and anesthesia histories will result in improvements in patient outcomes.

\section{Disclosure}

No funds were received in support of this work. No benefits in any form have been or will be received from any commercial party related directly or indirectly to the subject of this manuscript.

Correspondence to: Massel DH, Professor, Department of Orthopaedic Surgery, Rush University Medical Center, 1611 W. Harrison St, Suite \#300, Chicago, IL Kern Singh, MD, Associate 60612, USA, Tel: 312-432-2373, Fax: 708- 492-5373; E-mail: Kern.singh@rushortho.com

Key words: anesthesia, anterior discectomy and fusion, commentary, facetectomy, laminectomy, outpatient surgery, spine surgery

Received: November 09, 2015; Accepted: November 20, 2015; Published: November 24, 2015 


\section{References}

1. Fosnot CD, Fleisher LA, Keogh J (2015) Providing value in ambulatory anesthesia. Curr Opin Anaesthesiol 28: 617-622. [Crossref]

2. Oppenheimer JH, DeCastro I, McDonnell DE (2009) Minimally invasive spine technology and minimally invasive spine surgery: a historical review. Neurosurg Focus 27: E9. [Crossref]

3. Skovrlj B, Gilligan J, Cutler HS, Qureshi SA(2015) Minimally invasive procedures on the lumbar spine. World J Clin Cases 3: 1-9. [Crossref]

4. Barbagallo GM, Albanese V, Raich AL, Dettory JR, Sherry N, et al. (2014) Lumbar Lateral Interbody Fusion (LLIF): Comparative Effectiveness and Safety versus PLIF/
TLIF and Predictive Factors Affecting LLIF Outcome. Evid Based Spine Care 5 5: 28-37. [Crossref]

5. Phan K, Rao PJ, Kam AC, Mobss RJ(2015) Minimally invasive versus open transforaminal lumbar interbody fusion for treatment of degenerative lumbar disease: systematic review and meta-analysis. Eur Spine J 24: 1017-1030. [Crossref]

6. Gan TJ, Meyer TA, Apfel CC, Chung F, Devis PJ, et al. (2007) Society for Ambulatory Anesthesia guidelines for the management of postoperative nausea and vomiting. Anesth Analg 105: 1615-1628. [Crossref]

7. Carroll NV, Miederhoff P, Cox FM, Hirsch JD (1995) Postoperative nausea and vomiting after discharge from outpatient surgery centers. Anesth Analg 80: 903-909. [Crossref]

Copyright: (C2015 Masse DH. This is an open-access article distributed under the terms of the Creative Commons Attribution License, which permits unrestricted use, distribution, and reproduction in any medium, provided the original author and source are credited. 